ISSN 1983-8484

Licenciado sob uma Licença Creative Commons

\title{
Estratégias de internacionalização: estudos de caso de empresas catarinenses
}

\author{
Internationalization strategies: case studies of corporations in Santa Catarina
}

Bernardo Meyer ${ }^{[a]}$, Victor Meyer ${ }^{[b]}$, Joelma Martins Matos ${ }^{[c]}$

[a] Doutor em Administração, coordenador e professor do curso de Administração, Faculdade Estácio de Sá de Santa Catarina, São José, SC - Brasil, e-mail: bernardo_meyer@hotmail.com

[b] Doutor em Administração, professor titular do Programa de Pós-Graduação em Administração da Pontifícia Universidade Católica do Paraná (PPAD/PUCPR), Curitiba, PR - Brasil, e-mail: v.meyer@pucpr.br

[c] Bacharel em Administração, administradora da Secretaria da Fazenda do Estado de Santa Catarina, SC - Brasil, e-mail: joelmamartins83@hotmail.com

\section{Resumo}

A internacionalização de empresas é um fenômeno recente no Brasil. As empresas brasileiras ainda estão aprendendo o caminho para a conquista de mercados externos. 0 sucesso nos mercados internacionais depende, dentre outros fatores, de estratégias que direcionem os esforços organizacionais para a conquista de vantagens competitivas nesses novos ambientes competitivos. Este estudo se fundamenta nas abordagens teóricas de Johanson e Vahlne (1977) e Hilal e Hemais (2003) quanto ao incrementalismo estratégico, na importância da utilização de intermediários no processo de internacionalização (KANTER; DRETLER, 1998), na adaptação estratégica a diferentes mercados e no processo de aprendizagem organizacional a que se referem Parker (1999) e Child (2003). 0 objetivo deste trabalho é examinar as principais estratégias de internacionalização de quatro das principais empresas exportadoras da região da Grande Florianópolis. Trata-se de estudo multicaso, de natureza qualitativa, em que foram entrevistados os gestores das empresas pesquisadas. A análise revelou que as empresas estudadas, inicialmente bem-sucedidas no mercado interno, implementaram, a partir de oportunidades identificadas no mercado externo, ações estratégicas específicas, adaptando-se às características do mercado internacional. A principal conclusão é a de que as empresas utilizaram estratégias adaptativas e de exportação direta, tendo o processo de internacionalização gerado um aprendizado organizacional que lhes tem permitido se manterem competitivas no mercado internacional.

Palavras-chave: Estratégias. Internacionalização. Empresas. Santa Catarina.

\section{Abstract}

The internationalization of companies is a recent phenomenon in Brazil. Brazilian companies are still learning how to conquer external markets. Among other factors, success in international markets depends on strategies 
that guide organizational efforts in order to gain competitive advantages in these new competitive environments. This study is based on the theoretical approaches of Johanson and Vahlne (1977) and Hilal and Hemais (2003) concerning strategic incrementalism, the importance of using intermediaries in the internationalization process (KANTER; DRETLER, 1998), strategic adaptation to different markets and the organizational learning process referred to by Parker (1999) and Child (2003). The aim of this study is to examine the main internationalization strategies of four of the major exporting companies in the Metropolitan Region of Florianópolis. It is a multi-case study of a qualitative nature, in which the managers of the companies in question were interviewed. The analysis revealed that the companies under study, initially successful in the internal market, having identified opportunities in the external market, implemented specific strategic actions to adapt to the international market. The main conclusion of the study is that the companies used adaptive strategies and direct export strategies, and that the internationalization process led to a form of organizational learning that enabled them to remain competitive in the international market.

Keywords: Strategie. Internationalization. Corporations. Santa Catarina.

\section{Introdução}

O mundo atual é caracterizado pela redução das barreiras comerciais, formação de blocos econômicos, intensa troca de bens e serviços e uma crescente integração econômica entre os países, apoiada em nova tecnologia da informação e comunicação. Este contexto tem contribuído para o desenvolvimento do comércio internacional e, consequentemente, o ingresso de um número crescente de empresas em mercados estrangeiros. Estas empresas se utilizam de matérias-primas e equipamentos importados nas suas operações, bem como têm aberto unidades operacionais em outros países ou, ainda, têm terceirizado suas operações para empresas localizadas em diferentes partes do globo. A utilização de práticas como o offshoring são cada vez mais comuns entre empresas em todo o mundo.

No Brasil esta realidade também não é diferente, pois cada vez mais empresas estão iniciando atividades relacionadas ao comércio internacional. No Estado de Santa Catarina, as empresas, por sua vez, sempre apresentaram uma inserção internacional maior do que em outras unidades da federação brasileira.

Florianópolis, tradicionalmente, tem se caracterizado como o centro administrativo, legislativo e judiciário do Estado de Santa Catarina, além de importante polo turístico e região que congrega um número crescente de empresas prestadoras de serviço. Mais recentemente, a partir da década de 90, se expande um núcleo de empresas de base tecnológica. Algumas destas empresas, especialmente aquelas cujos produtos apresentam forte componente tecnológico, têm desenvolvido esforços no sentido de levar seus produtos e serviços a mercados internacionais.

0 sucesso nos mercados internacionais depende, dentre outros fatores, de estratégias que direcionem os esforços organizacionais para a conquista de vantagens competitivas nos novos mercados. Estas estratégias, por sua vez, precisam estar ajustadas ao cenário internacional de modo a atingir sua eficácia, destacando-se que os mercados doméstico e internacional demandam estratégias diferenciadas.

O objetivo deste trabalho é analisar as principais estratégias de internacionalização de quatro empresas exportadoras, localizadas na região da Grande Florianópolis. Para isto, utilizou-se do estudo de caso, do tipo multicaso, como estratégia de pesquisa.

\section{Negócios internacionais}

A integração entre as nações e a redução nas barreiras comerciais entre os países, caracterizada pelos efeitos da globalização, dá início a uma fase de expansão nos negócios internacionais. Esta tendência de expansão nos negócios internacionais das empresas é observada em quase todos os países do mundo.

No Brasil, desde o começo da década de noventa, observa-se uma tendência das empresas em buscarem uma maior participação no mercado externo, até então pouco explorado. Na ótica de Aulakh, Kotabe e Teegen (2000), a globalização do ambiente de negócios, nos últimos anos, tornou a busca por 
oportunidades em mercados estrangeiros um imperativo para empresas que desejam obter e sustentar vantagens competitivas.

Um dos fatores que tem contribuído decisivamente para o aumento dos negócios internacionais, na percepção de Buckley e Ghauri (2004), é a terceirização de atividades produtivas das empresas multinacionais para empresas localizadas em outros países, com custos produtivos mais baixos. No contexto atual, de uma economia global, muitas grandes empresas multinacionais passaram a contar com empresas prestadoras de serviços espalhadas por várias partes do mundo, na sua rede de fornecedores e parceiros.

Este fato constituiu-se em um importante impulsionador do processo de internacionalização e organizações oriundas de países emergentes. Consequentemente, firmas de economias emergentes estão aumentando a sua presença na economia global (AULAKH; KOTABE; TEEGEN, 2000).

0 ingresso no mercado internacional vai além do simples objetivo de vender um produto para um cliente de outro país. É necessário estar preparado para enfrentar uma concorrência mais eficaz e clientes mais exigentes que o habitual. Neste particular, Kuazaqui $(1999$, p. 35) destaca que "todos aqueles que desejam exportar devem avaliar os riscos inerentes ao país, assim como à empresa que está comprando seus produtos ou serviços".

As empresas, ao ingressarem em um mercado global estarão correndo riscos maiores, pois necessitarão investir quantias consideráveis para se manterem competitivas e garantir o sucesso dos seus produtos no exterior. Em função disto, Kotler e Armstrong (1998) justificam que, devido aos riscos e dificuldades de entrar em mercados internacionais, a maioria das empresas só se internacionaliza depois que alguma situação a impulsione para a arena global. Já Keegan e Green (2003) aconselham toda e qualquer organização, nos dias de hoje, esteja ela atuando no mercado internacional ou não, a pensar globalmente e atuar localmente.

Por esta razão, empresas que atuam no mercado global precisam ter atenção especial a fatores políticos, culturais, econômicos, legais e sociais dos países onde atuam. Em julho de 2006, por exemplo, a empresa brasileira Petrobras foi surpreendida na Bolívia por um decreto presidencial que nacionalizava algumas das suas operações naquele país. Ao comentar este tema, Meyer (2006) enfatiza que esta decisão do governo boliviano foi recebida no Brasil com surpresa, justamente porque a Petrobras era, naquele momento, a maior empresa estrangeira em atuação na Bolívia, com investimentos de mais de um bilhão de dólares no país.

A concorrência nos mercados internacionais também é uma variável que preocupa as empresas que se internacionalizam. Para Almeida, Oliva e Ramos (2005), no contexto atual de economia globalizada, é praticamente impossível impedir a entrada de concorrentes internacionais em qualquer mercado. Os mesmos autores destacam que os governos dos países necessitam estimular as empresas nacionais a aprimorarem suas técnicas de administração e produção para tornarem-se mais competitivas perante seus concorrentes transnacionais.

Neste cenário de globalização e de intensa competição, a preocupação com nacionalidade de empresas, produtos e serviços perde a sua importância. Para Ohmae (1999), cada vez mais, as pessoas estão menos preocupadas com a origem dos produtos ou das suas fábricas, voltando sua maior atenção para suas marcas e qualidade.

O êxito nos mercados internacionais irá depender, em grande parte, da capacidade das empresas desenvolverem seu planejamento adequando suas estratégias às especificidades dos novos mercados. 0 mundo dos negócios internacionais está aberto àqueles que tiverem competência para conquistá-lo.

\section{Estratégias de internacionalização}

Qualquer empresa necessita de estratégias específicas no seu processo de internacionalização. Estratégias utilizadas com sucesso no mercado interno não se aplicam aos negócios internacionais. 0 contexto internacional, por ser mais amplo e complexo exige competências e habilidades dos gestores para que sejam bem-sucedidos em suas novas ações no mercado externo. Parker (1999) reforça este argumento ressaltando que a globalização exige novas abordagens para a formulação de estratégias.

Buckley e Ghauri (2004) acrescentam que empresas que estão se internacionalizando estão utilizando-se de estratégias mais diversificadas e abrangentes para coordenar as suas atividades globais. Estas estratégias variam desde parcerias até aquisição de ativos internacionais.

Hilal e Hemais (2003) enfatizam a abordagem da escola nórdica ao processo de internacionalização de 
empresas, que se caracteriza por sua natureza incremental, permitindo a uma organização se beneficiar da aprendizagem sucessiva por meio de etapas de comprometimento crescente com o mercado estrangeiro, ao invés de uma sequência de passos planejados e deliberados. Como representantes da escola nórdica, Johanson e Vahlne (1977) afirmam que as empresas suecas desenvolvem operações internacionais em pequenos passos ao invés de se utilizarem de grandes investimentos pontuais.

Ghemawat (2008) identifica quatro diferentes tipos de estratégia para criar valor em empresas que se internacionalizam: a) as estratégias adaptativas que são utilizadas para ajustar os produtos e serviços ofertados às exigências específicas de cada mercado; b) as estratégias de agregação que são utilizadas para agrupar mercados em função de suas similaridades visando gerar economias de escala; c) estratégias de arbitragem são utilizadas para explorar as diferenças que existem entre os países ao invés de tratá-las como restrições; d) a chamada estratégia "AAA", que permite que as organizações integrem as abordagens das estratégias adaptativas, de agregação e de arbitragem para buscar maior vantagem competitiva.

A abordagem da escola nórdica torna evidente a importância do aprendizado organizacional durante o processo de internacionalização. Segundo Parker (1999), a organização que atua internacionalmente precisa utilizar-se, sempre que possível, da aprendizagem organizacional para desenvolver estratégias, competências e habilidades baseadas nas experiências internacionais da empresa e de seus agentes. Uma organização que é eficaz em sua aprendizagem será tanto capaz de criar, adquirir e transferir conhecimento, assim como modificar o seu comportamento para refletir este novo conhecimento (CHILD, 2003).

A tecnologia é outro elemento que contribui sobremaneira para o desenvolvimento de estratégias internacionais. De acordo com Buckley e Ghauri (2004), o contexto atual continua promovendo a internacionalização das empresas de menor porte, uma vez que o desenvolvimento das tecnologias de comunicação tem facilitado o acesso e a busca por novos clientes.

Outro elemento importante nas estratégias de internacionalização é o conceito de distância psíquica. Para Hilal e Hemais (2003), a distância psíquica percebida pelo executivo afeta a sua análise de variáveis como barreiras a exportação, risco das operações, avaliação do potencial de mercado, confiança na possibilidade de sucesso, formação de redes sociais e políticas.

Johanson e Vahlne (1977) destacam que distância psíquica é a soma de fatores que atrapalham o fluxo de informação de um mercado para o outro. Destacam-se aqui elementos como diferenças na linguagem, na educação, nas práticas administrativas, na cultura e no desenvolvimento industrial. Estes fatores fazem com que a complexidade de se atuar nos mercados internacionais seja mais elevada do que no âmbito doméstico, em razão do maior número de elementos que interferem no processo de comunicação entre partes localizadas em diferentes países, exigindo estratégias diferenciadas.

Ao analisar organizações que iniciam sua internacionalização, Faulkner (2003) enfatiza que há uma tendência de realizar negócios com empresas localizadas em países culturalmente semelhantes aos seus. Isto pode ser explicado pelo fato de se acreditar que o nível de incerteza aumenta com o aumento da distância psíquica. Hilal e Hemais (2003) destacam que as empresas que se internacionalizam buscam alternativas para se sentirem menos estrangeiras possíveis.

O sucesso da operação internacional de uma organização irá depender da capacidade de adaptar suas operações, seus produtos e serviços à realidade do país hospedeiro. Kogut (2002) argumenta que a empresa que atua em vários países precisa desenvolver flexibilidade para se adaptar às exigências dos mercados nacionais. Rowley e Benson (2002), em estudo sobre administração de recursos humanos em quatro diferentes países asiáticos, concluíram que é difícil universalizar as práticas de gerenciamento de pessoas em diferentes países devido a variáveis culturais, sendo necessário, por esta razão, tratar cada país de forma individualizada. Ao pesquisarem o impacto das diferenças culturais em empresas multinacionais holandesas, Drogendijk e Slangen (2006) reforçam o entendimento de que a distância cultural é um fator dificultador na instalação de empresas multinacionais em países estrangeiros, independentemente da experiência internacional ou do tamanho da empresa.

Quando empresas se internacionalizam, é comum haver uma tensão entre se globalizar ou se manter local respondendo aos seus clientes tradicionais. A vantagem de se tornar global é relativa a custos, economia de escalas e aumento de eficiência. Já a vantagem de se tornar local se encontra na capacidade 
de promover diversificação e conseguir atingir diferentes nichos de mercado (BUCKLEY; GHAURI, 2004). Em se tratando de estratégias internacionais, Levitt (1983) reforça o entendimento de que sempre haverá necessidade de se acomodar as diferenças entre os países e regiões, apesar da tendência mundial de homogeneização de produtos e serviços.

Ao examinar a vantagem competitiva das empresas, Barney (1991) enfatiza a importância das empresas se concentrarem nos recursos organizacionais para obterem vantagens competitivas sustentáveis. Estes recursos são identificados como físicos, humanos e organizacionais. $\mathrm{O}$ autor reforça o entendimento de que a vantagem competitiva de uma organização se sustenta com base em recursos, com os seguintes atributos: valiosos, raros e de difícil imitação. 0 principal objetivo das empresas é formular e desenvolver estratégias que proporcionem vantagem competitiva sustentável, combinando, para isto, o uso destes recursos, de forma única e diferenciada, evitando a sua imitação.

Uma das formas de internacionalização mais utilizadas pelas pequenas e médias empresas se dá por meio da exportação de produtos e serviços. Esta estratégia vem a ser utilizada devido a seu baixo custo e menor complexidade na sua implementação, quando comparada, por exemplo, a investimento internacional ou licenciamento.

\section{Exportação}

A expansão do comércio internacional tem contribuído para um considerável aumento nas importações e exportações. No Brasil, esta tendência não tem sido diferente, observando-se, nos últimos anos, um incremento nas exportações do País.

Há um entendimento de que a exportação é a porta de entrada para o mundo do comércio internacional. Para Kotler e Armstrong (1998), a exportação é a maneira mais simples de uma empresa entrar em um mercado internacional. Os referidos autores ainda alertam que a exportação é a opção que envolve a menor mudança nas linhas de produto, na organização, nos investimentos ou na missão da empresa.

Existem também outras vantagens na atividade exportadora. Vazquez (1999), por exemplo, acredita que o principal motivo para exportar é obter recursos para pagamento das importações necessárias para vida econômica da empresa. Vasquez revela ainda que outros motivos têm levado as organizações à atividade exportadora, como o interesse do empresário em aumentar o leque de clientes da empresa, quer por razões de saturação do mercado interno, quer por escoamento do excesso de produção, ou mesmo para diluir a dependência em relação a um determinado mercado.

Mesmo aquelas empresas que apresentam um baixo percentual de vendas externas competem, em seus mercados domésticos, com empresas internacionais, tendo como base padrões internacionais de qualidade como forma de garantir o mercado no seu país de origem (KANTER; DRETLER, 1998). Nesta mesma linha de argumentação Kotler e Armstrong (1998, p. 435) alertam que "a empresa que acha que não é seguro expandir-se para o exterior não só perde a chance de entrar em outros mercados como também se arrisca a perder o seu mercado interno".

Uma dificuldade encontrada na internacionalização de empresas de países emergentes é a percepção negativa acerca da qualidade dos produtos e serviços oriundos destes países por parte dos clientes dos mercados dos países desenvolvidos. Ao estudarem este tema, Aulakh, Kotabe e Teegen (2000) mencionam que produtos oriundos de países emergentes são associados a preço e qualidade baixos entre os consumidores de mercados desenvolvidos.

Em se tratando de exportação, é preciso identificar os seus formatos. Para Dabbah (1998) existem basicamente duas formas de comercialização de produtos no exterior: direta e indireta. A forma direta ocorre quando a empresa vende seus produtos ou serviços sem a participação de revendedores, enquanto que a forma indireta torna indispensável a participação destes revendedores.

Sobre os tipos de exportação, Kotler e Armstrong (1998) complementam afirmando que as empresas geralmente costumam começar com exportações indiretas, utilizando-se de intermediários internacionais independentes. Os mesmos autores explicam que a exportação indireta requer menos investimento, pois a empresa não precisa de uma força de vendas internacional e envolve menos riscos.

Em relação a formas diretas de comercialização, Dabbah (1998) ressalta que, neste caso, o fabricante coloca seus produtos diretamente no exterior, assumindo os riscos da operação. Para Kotler e Armstrong (1998), a vantagem deste tipo de comercialização é que permite um maior controle das próprias exportações.

No entendimento de Dabbah (1998) há ainda outras formas de comercialização direta que podem ser 
utilizadas pelas empresas na sua internacionalização. 0 autor destaca como exemplos a participação em feiras internacionais, o uso de distribuidores para seus produtos, a utilização de agentes comerciais, a abertura de escritórios de vendas em outros países, o estabelecimento de empresas afiliadas, a contratação de serviços de empresas de consultoria, a formação de consórcios de exportação e, por último, a assessoria de corretores de mercadorias, mais conhecidos como brokers.

Em seu estudo de empresas brasileiras que se internacionalizaram, Hilal e Hemais (2003) reforçam o entendimento de que a utilização de redes pessoais e agentes tem sido crítica para a abertura de novos mercados. Em relação a mercados considerados longínquos e difíceis de atuar, como o asiático e o do leste europeu, percebeu-se a predominância do uso de distribuidores para os produtos. Na visão de Johanson e Vahlne (1977), a estratégia de comercialização faz parte de um processo evolutivo, já que tipicamente uma empresa inicia sua internacionalização exportando seus produtos e serviços por meio de agentes comerciais. Em seguida, a empresa estabelece uma subsidiária de vendas exterior e, em alguns casos, instala unidades produtivas no país hospedeiro.

Kanter e Dretler (1998) destacam a importância das redes de relacionamento internacionais, com os agentes e distribuidores, por exemplo, como fontes geradoras de novas estratégias. Os mesmos autores acreditam ser importante buscar novos conceitos no âmbito internacional para incentivar a inovação e facilitar a inserção em novos mercados.

A exportação constitui-se, assim, em alternativa para empresas que desejam iniciar suas atividades no mercado externo. Certamente essas empresas necessitam ter presente que as vendas por exportação são mais complexas que as vendas no mercado doméstico, por envolverem um número maior de variáveis, como as econômicas, tecnológicas, políticas e culturais.

\section{Metodologia}

Este trabalho caracteriza-se como um estudo de caso do tipo multicaso. Baseia-se na experiência de quatro empresas brasileiras, localizadas na região metropolitana de Florianópolis, de médio porte, que se encontram em fase de consolidação de sua experiência no comércio internacional. 0 estudo examina o caso das empresas Incema Indústria e Comércio Ltda.,
Olsen Indústria e Comércio S.A., Dígitro Tecnologia Ltda. e Macedo Koerich S.A.

A importância do estudo de caso como estratégia de pesquisa, segundo Eisenhardt (1989), está no fato deste tipo de estudo ter como foco o entendimento das dinâmicas presentes em um determinado ambiente ou em um grupo deles. Já Yin (2001) destaca que o estudo de caso deve ser a estratégia utilizada para se examinar acontecimentos contemporâneos, sem manipular os comportamentos mais relevantes para o estudo. Ainda em relação à importância do estudo de caso, Remenyi et al. (2002) afirmam que esta estratégia deve ser utilizada porque permite um entendimento mais holístico do problema, além de proporcionar uma exploração mais significativa das características de um evento real.

O objetivo deste estudo foi examinar as principais estratégias de internacionalização de quatro empresas exportadoras brasileiras, localizadas na região metropolitana de Florianópolis. 0 estudo caracteriza-se como uma pesquisa de natureza qualitativa e baseia-se em entrevistas semiestruturadas realizadas com os administradores responsáveis pela área de comércio exterior das empresas estudadas. Procurou-se obter a percepção dos administradores quanto aos diversos fatores relativos a essa atividade, com destaque para as estratégias desenvolvidas e fatores que afetaram sua inserção no mercado internacional. $\mathrm{O}$ instrumento de coleta de dados foi testado e considerado válido para aplicação. As entrevistas foram realizadas no período de janeiro a fevereiro de 2006, tendo sido entrevistados um total de doze gestores, correspondendo a quatro gestores por empresa estudada. Um dos entrevistados, em cada empresa, era responsável pelo departamento de exportação. A escolha dessas empresas baseou-se em amostra intencional dentro de um grupo das maiores empresas exportadoras na região. Além das entrevistas, foi realizada a análise de dados secundários, tendo sido examinados os sites de internet das empresas pesquisadas e periódicos de circulação no Estado de Santa Catarina, como o jornal Diário Catarinense e a Gazeta Mercantil da região sul.

A empresa Olsen Indústria e Comércio S.A., fundada em 1978, atua no ramo de equipamentos odontomédicos e iniciou sua incursão no mercado internacional em 1994, por meio de participações em feiras e congressos. 0 produto já havia incorporado e consolidado qualidade técnica e a Olsen oferecia ao mercado equipamentos com alta tecnologia e design. 
As exportações representam $50 \%$ da produção e a internacionalização de seus produtos já atingiu a marca de mais 100 países. Segunda maior fabricante de equipamentos médicos e odontológicos da América Latina, a empresa Olsen S.A. pretende impulsionar seus resultados na pauta de exportação. A receita com exportações tem crescido significativamente nos últimos anos, sendo objetivo da empresa destinar $60 \%$ dos seus produtos para o mercado externo no médio prazo. 0 sucesso em países como Cuba, Chile e Venezuela levaram a empresa a considerar a expansão das suas exportações para outros países da América do Sul.

A Macedo Koerich S.A., considerada uma importante empresa no ramo alimentício no Estado de Santa Catarina, atua há 32 anos produzindo frangos e seus derivados, atendendo aos padrões internacionais vigentes em segurança alimentar. Possui uma ampla infraestrutura, composta de uma central de armazenagem de grãos, duas fábricas de ração, uma granja de matrizes, um incubatório, um frigorífico e quatro centrais de distribuição. Além de granjas integradas, parceiras e dos incubatórios terceirizados. No mercado internacional, atende aproximadamente 50 clientes espalhados em mais de 20 países. 0 primeiro negócio para exportação de seus produtos foi fechado com a Espanha em meados da década de noventa.

A Incema Indústria e Comércio de Móveis Ltda. iniciou suas atividades em 1984, tendo reunido, ao longo de sua existência, uma sólida experiência na indústria moveleira. Desde 1993 a empresa vende seus produtos, exclusivamente, no mercado externo, adicionando ao seu perfil recursos como credibilidade, capacidade e qualidade exigidos pelo mercado internacional. Suas duas unidades fabris, localizadas no sul do Brasil, conferem à Incema o título de uma das maiores indústrias exportadoras de camas e beliches do Brasil. Seus produtos podem ser encontrados no continente europeu, na América do Norte, América do Sul e Austrália. Com o intuito de assegurar uma alta qualidade de seus produtos, a Incema tem buscado, de forma permanente, melhorias tecnológicas e qualificação de sua mão de obra. Apoiada em estrutura flexível, a empresa desenvolveu a capacidade de se adaptar às mais rígidas especificações dos mercados em que atua, oferecendo projetos exclusivos a clientes e mercados específicos.

A empresa Dígitro Tecnologia Ltda., fundada em 1977, atua no ramo de serviços em telecomunicações, já tendo conquistado grandes prêmios e reconhecimento do mercado nacional. Dentre as empresas pesquisadas é a que tem a menor experiência no mercado internacional, uma vez que iniciou somente em 2003, por meio de parceira com a empresa uruguaia Teleimpresores, suas atividades de exportação. Em três anos a empresa já conquistou países como Argentina, Paraguai, Panamá, El Salvador e Colômbia. Em relação a este assunto, Costa (2006) destaca que a empresa traçou um plano de conquistar a América Latina até o ano de 2010, expandindo para países como México, Chile, Equador, Venezuela, Honduras e Peru.

\section{Análise e discussão dos dados}

Vários são os fatores que têm influenciado a internacionalização das empresas brasileiras. Este estudo examinou os fatores presentes em duas dimensões: dimensão interna da organização e dimensão mercadológica. Observou-se que as empresas estudadas estão recém descobrindo o comércio internacional, tendo desenvolvido, no período de 1993-2003, as primeiras atividades de expansão além das fronteiras nacionais.

Conforme o Quadro 1, com exceção da empresa Dígitro Tecnologia, cuja experiência no mercado externo é mais recente, iniciada somente a partir de 2003, as demais empresas pesquisadas iniciaram suas exportações na década de noventa, concomitantemente com a abertura do mercado nacional pelos governos da época. A empresa Incema exporta $100 \%$ de sua produção, desde 1993, quando deixou de atender ao mercado interno. As empresas Olsen e Macedo Koerich buscaram no período examinado um equilíbrio entre os mercados interno e externo e, por isto, exportam em torno de $50 \%$ de sua produção. Já a Dígitro Tecnologia exportou, no ano de 2005, apenas $5 \%$ de sua produção. Estes dados demonstram que há uma relação entre tempo de atuação no mercado internacional e participação das exportações sobre sua produção total.

É importante ressaltar que o tamanho do departamento encarregado de comércio exterior em cada uma das organizações pesquisadas está mais relacionado às particularidades do mercado de atuação do que em relação ao valor percentual exportado ou mesmo ao tempo de atuação no mercado externo. Observou-se, na empresa Macedo Koerich, a existência de um departamento com dez pessoas. Este pode 
MEYER, B.; MEYER, V.; MATOS, J. M.

Quadro 1 - Percentual de exportações em relação à produção das empresas, em 2005

\begin{tabular}{lc}
\hline Empresa & Exportações/Produção (\%) \\
\hline Dígitro Tecnologia & 5 \\
Incema & 100 \\
Macedo Koerich & 50 \\
Olsen & 50 \\
\hline
\end{tabular}

Fonte: Dados da pesquisa.

ser considerado relativamente amplo, em termos de tamanho, se comparado com a empresa Incema, que dispõe de apenas dois funcionários atuando nesta área para realizar a exportação total da produção. $\mathrm{Na}$ empresa Dígitro Tecnologia, por sua vez, cinco pessoas estão ligadas diretamente à área de comércio exterior.

A falta de profissionais habilitados para atuar no mercado internacional tem sido um dos principais problemas apontados pelas empresas. Destaque-se que na região da Grande Florianópolis ainda não existem instituições que ofereçam formação específica para o desenvolvimento de profissionais da área, assim como também falta experiência a estes profissionais. Fato este que obriga empresas, como a Dígitro Tecnologia, a buscar profissionais fora do mercado regional e, muitas vezes, fora do mercado nacional.

0 estudo revelou que, além da falta de profissionais, as empresas enfrentam outra grande dificuldade: a burocracia imposta pelo governo para se ter acesso aos recursos de incentivo à exportação. Como apontado pelos gestores entrevistados, muitas barreiras burocráticas são impostas para que as empresas consigam, por exemplo, obter a isenção de alguns impostos através do drawback.

Segundo o Quadro 2, as empresas Incema, Dígitro Tecnologia e Olsen estão aptas a solicitar a isenção de impostos por meio do drawback, pois importam matéria-prima para a produção de seus produtos, mesmo que em pequenas quantidades. Os insumos utilizados pela Dígitro Tecnologia e pela Olsen têm origem na Europa e nos Estados Unidos, enquanto a matéria-prima utilizada pela Incema é originária da Argentina. A empresa Macedo Koerich busca alternativas para importar insumos para serem utilizados na embalagem dos frangos, conseguindo com isto o direito de utilização do drawback, o que torna o seu produto ainda mais competitivo. Pode-se perceber que a maioria das empresas pesquisadas se utiliza de matéria-prima importada nos seus produtos e, portanto, se beneficia do drawback como forma reduzir seus gastos com impostos.

Outra dificuldade enfrentada, principalmente pelas empresas que atuam na área tecnológica, é a grande concorrência no mercado externo, uma vez que empresas norte-americanas e europeias, em geral, lideram este mercado. É reconhecida a competitividade destas empresas devido à alta qualidade e grande desenvolvimento tecnológico, fazendo com que seus produtos se destaquem, o que dificulta a entrada de produtos brasileiros em seus territórios. Soma-se a isto o que já foi destacado por Aulakh, Kotabe e Teegen (2000) sobre a discriminação que sofrem os produtos oriundos de países emergentes em mercados de países desenvolvidos.

Quadro 2 - Utilização de matéria-prima importada e sua origem

\begin{tabular}{lcc}
\hline Empresa & Utiliza matéria-prima importada? & Origem \\
\hline Dígitro Tecnologia & Sim & Europa e EUA \\
Incema & Sim & Argentina \\
Macedo Koerich & Não & - \\
Olsen & Sim & Europa e EUA \\
\hline
\end{tabular}

Fonte: Dados da pesquisa. 
Como se observa no Quadro 3, essas dificuldades apontadas no estudo foram determinantes para que as empresas Dígitro Tecnologia e Olsen buscassem espaço, inicialmente, no mercado latino-americano, conquistando países como a Argentina e o Chile. A empresa Dígitro Tecnologia, que atua no setor de telecomunicações, atende apenas ao mercado dos países latino-americanos, porém já possui planos de expansão de seus serviços ao mercado europeu.

A empresa Olsen, fabricante de equipamentos odontológicos e ginecológicos, enfrenta uma situação de concorrência menos intensa do que a Dígitro Tecnologia, por atuar em um mercado mais específico. Atualmente, além do mercado latino-americano, seus produtos já estão presentes na Europa, Ásia e África.

A análise das empresas de tecnologia aponta para o fato de a empresa Olsen enfrentar uma concorrência menor do que a empresa Dígitro Tecnologia, o que tem permitido que sua atuação internacional seja mais intensa. 0 mercado de telecomunicações na Europa e nos Estados Unidos da América, por exemplo, é mais concorrido do que o mercado de produtos médicos e odontológicos, e por esta razão apresenta maiores dificuldades de acesso e captação de clientes.

Ao se analisar os vários segmentos de atuação das empresas pesquisadas pode-se constatar que os produtos e serviços por elas oferecidos estão presentes em todas as partes do globo, como África, América Latina, Europa, América do Norte, Ásia e Oceania. Este fato demonstra a amplitude da atuação internacional das empresas foco do estudo.

Apesar desta variedade de mercados de atuação, as empresas pesquisadas identificaram como uma grande ameaça à sua expansão internacional a variação da moeda brasileira diante do dólar. Variações no câmbio podem aumentar os custos de produção e, assim, diminuir a competitividade dos seus produtos no exterior. A empresa Incema, por exemplo, teve, muitas vezes, dificuldades para repassar aos seus clientes o aumento do custo do produto devido às variações cambiais.

Uma das empresas estudadas, a Macedo Koerich, enfrentou outra grande ameaça, a Gripe do Frango. Esta epidemia que, em 2005, atingiu cidades da Ásia, Europa e África, trouxe sérios prejuízos para a economia mundial, em especial para o comércio internacional. A ameaça de disseminação em escala global fez com que o consumo de frangos, em todo o mundo, fosse reduzido, fato que impediu que a empresa alcançasse os objetivos de crescimento traçados para 2006.

Quanto às estratégias utilizadas pelas empresas pesquisadas para atuar no mercado internacional, observou-se que em duas delas, Dígitro e Incema, o início da atuação no mercado internacional deveu-se a circunstâncias que não haviam sido planejadas. Essas empresas não possuíam planos para uma expansão internacional quando foram surpreendidas por um convite para exportarem para outros mercados, iniciando, assim, atividade no comércio internacional. Este comportamento reforça a presença de estratégias emergentes, como apontado por Mintzberg e Waters (1985), também no âmbito internacional.

0 estudo revelou que durante algum tempo as empresas pesquisadas tiveram que superar muitas dificuldades, de ordem interna e mercadológica, de maneira a adaptar seus produtos e serviços às demandas de novos mercados. Este fato fortalece a abordagem da escola nórdica que se assenta na premissa de que a internacionalização é um processo não planejado e incremental, conforme descrito por Hilal e Hemais (2003).

A Incema atuava, exclusivamente, no mercado nacional vendendo madeiras de cacharia. No entanto, para atender o mercado internacional a empresa realizou uma mudança estratégica na sua linha de produtos. Neste sentido aceitou o desafio de diversificar sua carteira de produtos passando também a produzir móveis, visando tirar proveito de uma

Quadro 3 - Destino das exportações

\begin{tabular}{ll}
\hline Empresa & Destino das exportações \\
\hline Dígitro Tecnologia & América Latina \\
Incema & Europa, Oceania, América do Norte e América do Sul \\
Macedo Koerich & Não especificou (20 países) \\
Olsen & Europa, Ásia, África e América Latina \\
\hline
\end{tabular}

Fonte: Dados da pesquisa. 
oportunidade surgida no exterior. Esta mudança provocou uma reorganização dos recursos internos da empresa procurando alinhar estratégias organizacionais, recursos e capacidade, como destacam Barney (1991) e Child (2003). Mesmo sem experiência a empresa conseguiu adaptar-se fazendo do comércio internacional seu principal negócio, e passando a atender, exclusivamente, clientes do mercado externo. A decisão de destinar a produção inteiramente ao comércio internacional, para a Incema, mostrou-se vantajosa e bastante lucrativa.

Outras empresas, como a Macedo Koerich, que apesar de atender no Brasil apenas aos Estados do sul e ter metade de sua produção destinada ao mercado externo, não tem demonstrado interesse em direcionar a totalidade de sua produção ao mercado externo. A empresa teme aumentar a participação das exportações no total de vendas, tornando-se dependente do mercado alimentício internacional, com suas muitas especificidades e condicionantes.

Nas demais empresas estudadas, o fator mais relevante que as leva à prática da exportação deve-se à necessidade de ampliar seus mercados, em razão da existência de demanda por seus produtos no exterior. Nestes casos, o mercado nacional não se mostrava suficiente para absorver todos os produtos produzidos pelas empresas.

Outra característica que pode ser atribuída a todas as empresas pesquisadas é a de não possuir escritórios, filiais ou estruturas físicas em outros países. As mesmas buscam evitar maiores investimentos, uma vez que o custo para manter estas estruturas é bastante elevado. As empresas pesquisadas preferem não utilizar-se de grandes investimentos enquanto estão na fase de exportação de seus produtos.

Para superar a falta de estrutura no mercado internacional, as empresas buscam o apoio de agentes, distribuidores e varejistas que possam representá-las. Estes são profissionais experientes que atuam nos mercados locais. Trata-se de agentes, que se utilizam de suas experiências no mercado local, evitando o desperdício de tempo e investimentos. Além disto, os agentes ainda dão feedback para as empresas auxiliando-as a adequar os seus produtos às inovações e às exigências dos mercados internacionais, como já destacado por Kanter e Dretler (1998).

A inserção de produtos em novos mercados pode acarretar na necessidade de adaptações para atender às novas exigências. A empresa Macedo Koerich, por exemplo, foi além de uma simples adaptação e precisou modificar toda sua estrutura de abate de frangos para atender o mercado do Oriente Médio. A empresa, juntamente com representantes de seus clientes no Oriente Médio, projetou a reestruturação no departamento de abate de frangos, de forma a direcioná-los à cidade de Meca, respeitando os costumes da cultura muçulmana presentes naquela região.

Para chegar ao mercado internacional, as empresas estudadas realizaram pesquisas de mercado com o objetivo de identificar os potenciais mercados a serem atendidos. Após esta identificação, foram utilizadas outras estratégias, como a contratação de agentes e representantes. Este foi o caso típico das empresas Dígitro Tecnologia, Incema e Olsen.

Tanto a utilização de intermediários locais quanto as adaptações realizadas pelas empresas para atender às exigências dos novos mercados reforçam as abordagens de Kogut (2002) e Levitt (1983), como também contribuem para a diminuição da distância psíquica, conforme ressaltam Hilal e Hemais (2003) e Johanson e Vahlne (1977).

Outra prática utilizada é a divulgação de seus produtos e marcas em periódicos locais, como é feito pela empresa Olsen. A utilização de material promocional, como folders e catálogos enviados por e-mail e via correio, é outra prática que tem sido utilizada pela Incema para estimular suas vendas no exterior.

As quatro empresas estudadas têm praticado a exportação direta conforme descrita por Dabbah (1998), Kotler e Armstrong (1998). No entanto, estas empresas diferem entre si na forma como conduzem este tipo de exportação. A relação com os agentes ou representantes são diferentes em cada uma das empresas analisadas. A Dígitro Tecnologia, por exemplo, busca agentes que trabalhem para seus concorrentes e que possam no futuro migrar para uma representação exclusiva de seus produtos. Já a Olsen trabalha com representantes exclusivos, com dedicação total a sua marca. Ambas as empresas corroboram a evidência demonstrada no trabalho de Hilal e Hemais (2003) de que agentes e contatos comerciais auxiliam as empresas brasileiras a abrirem novos mercados.

As empresas Incema e Macedo Koerich, por sua vez, apesar de utilizarem agentes e representantes comerciais em alguns mercados internacionais, evitam utilizá-los, sempre que possível. Estas duas empresas acreditam que este procedimento diminui a sua margem de lucratividade e, por esta razão, têm procurado vender diretamente, evitando a participação de intermediários. 
Outra estratégia utilizada pelas empresas e apontada como eficaz é a participação nas feiras internacionais. Estas se constituem em grandes oportunidades de negócios, ao permitirem a disseminação da marca da empresa, a ampliação das redes de contato, além de contribuir para um melhor conhecimento dos seus concorrentes. No entanto, esta estratégia vem sendo utilizada com diferente intensidade pelas empresas estudadas.

Em relação às feiras internacionais, todas as empresas buscam participar das mais importantes para os seus setores. A Macedo Koerich e a Incema, que vendem seus produtos a grandes varejistas no mercado internacional, têm estado presentes nas principais feiras internacionais por meio destes clientes. Esta ação tem se mostrado bastante vantajosa por diminuir, consideravelmente, os custos de participação nas feiras, podendo direcioná-los a outros investimentos. As demais empresas procuram participar das mesmas com estrutura e investimento próprios.

Os mercados que apresentam maior poder de compra e grande mercado consumidor recebem uma maior atenção das empresas pesquisadas. Afinal, representam os mercados que oferecem uma maior rentabilidade e possibilidade de ganho a estas empresas. Assim, por exemplo, a empresa Olsen tem procurado focar suas atividades internacionais nos países da Europa Ocidental.

Conclui-se que as empresas catarinenses estudadas têm se mostrado capazes de expandirem-se além das barreiras nacionais, desenvolvendo estratégias competitivas de maneira a atender às demandas e particularidades de cada mercado, além de apresentarem grande potencial de crescimento. As competências desenvolvidas pelas empresas desenvolvidas no mercado internacional estão assentadas em recursos organizacionais que foram desenvolvidos antes do processo de internacionalização. As vantagens competitivas adquiridas na atuação no mercado doméstico permitiram que as empresas pesquisadas tivessem condições de atuar, com competitividade, em mercados internacionais. Este fato reforça a abordagem de Barney (1991), que relaciona recursos organizacionais, estratégias e vantagens competitivas.

\section{Conclusões}

0 ingresso de empresas no mercado internacional exige mudanças e estratégias específicas. Neste estudo foram examinadas as experiências de quatro empresas brasileiras que estão iniciando sua trajetória de conquista de mercados internacionais. Observou-se que as principais estratégias desenvolvidas por essas empresas foram de cunho adaptativo, conforme descrito por Ghemawat (2008), e voltadas à exportação de produtos e serviços de forma direta, mas com a utilização de agentes comerciais. Estas estratégias se revelam típicas de organizações que iniciam sua internacionalização sem a realização de grandes investimentos.

Algumas das empresas analisadas não ingressaram no mercado internacional de forma planejada e estruturada, mas acabaram por adotar estratégias incrementais como resposta às demandas específicas do mercado externo. Ao combinarem oportunidades no mercado externo, adequação de recursos internos e capacidade de mudança, as empresas pesquisadas se mostraram capazes de competir no mercado exterior. A quase totalidade das empresas estudadas permaneceu atuando no mercado brasileiro e reservando uma parte de sua produção ao mercado externo. Somente uma das empresas estudadas passou a atuar, exclusivamente, no mercado internacional.

Observa-se uma convergência das empresas pesquisadas em relação a outras duas ações estratégicas. A primeira é a utilização de pesquisas de mercado para auxiliar na identificação de mercados potenciais para os seus produtos. A segunda é a participação em feiras comerciais internacionais como estratégia de inserção da marca, dos produtos e serviços no mercado internacional.

A experiência de internacionalização das empresas foco do estudo revela claramente que as estratégias desenvolvidas neste esforço produziram um importante aprendizado organizacional. Enquanto algumas estratégias se identificaram como incrementais (HILAL; HEMAIS, 2003; JOHANSON; VAHLNE, 1977), outras se caracterizaram como emergentes (MINTZBERG; WALTERS, 1985), mas todas se revelaram importantes para a conquista de mercados novos e desconhecidos.

As principais estratégias utilizadas pelas empresas estudadas são identificadas como adaptativas e de exportação direta. Este fato reflete o que já vem acontecendo com um grande número de empresas que muitas vezes são procuradas por potenciais clientes de outros países e acabam iniciando desta forma a sua internacionalização. A internacionalização, que não era um objetivo da empresa, passa a ser 
incorporada como um novo objetivo organizacional, exigindo rápidas mudanças internas e o desenvolvimento de estratégias competitivas que produzam vantagens competitivas.

A experiência das empresas pesquisadas na sua inserção nos mercados internacionais tem sido exitosa. 0 sucesso futuro dependerá da combinação de atuais e novos recursos, que lhes permitam reforçar suas competências e manterem-se competitivas no dinâmico mercado internacional.

\section{Referências}

ALMEIDA, M. I. R.; OLIVA, F. L.; RAMOS, H. R. As estratégias das pequenas empresas diante dos desafios da globalização. In: CONGRESSO LATINOAMERICANO DE ESTRATÉGIA, 18. 2005, Santa Cruz de la Sierra. Anais... Santa Cruz de la Sierra, 2005. p. 16-29.

AULAKH, P. S.; KOTABE, M.; TEEGEN, H. Export strategies and performance of firms from emerging economies: evidence from Brazil, Chile and Mexico. The Academy of Management Journal, v. 43, n. 6, p. 342-361, 2000.

BARNEY, J. B. Firm resources and sustained competitive advantage. Journal of Management, v. 17, n. 1, p. 99-120, 1991.

BUCKLEY, P. J.; GHAURI, P. N. Globalisation, economic geography and the strategy of multinational enterprises. Journal of International Business Studies, v. 35, n. 2, p. 81-98, 2004.

CHILD, J. Organizational learning. In: FAULKNER, D. O.; CAMPBELL, A. The Oxford handbook of strategy. 2nd ed. New York: Oxford University Press, 2003.

COSTA, T. Dígitro quer conquistar a América. Gazeta Mercantil, p. 18, abril 2006.

DABBAH, S. A solução para sua empresa: exportação. 2. ed. São Paulo: Érica, 1998.

DROGENDIJK, R.; SLANGEN, A. Hofstede, Schwartz, or managerial perceptions? The effects of different cultural distances measures on establishment mode choices by multinational enterprises. International Business Review, v. 15, n. 4, p. 361-380, 2006.

EISENHARDT, K. M. Building theories from case study research. The Academy of Management Review, v. 14, n. 4, p. 532-550, 1989.
FAULKNER, D. International strategy. In: FAULKNER, D. 0.; CAMPBELL, A. The Oxford handbook of strategy. 2nd ed. New York: Oxford University Press, 2003.

GHEMAWAT, P. Redefinindo estratégia global: cruzando fronteiras em um mundo de diferenças que ainda importam. 2. ed. Porto Alegre: Bookman, 2008.

HILAL, A.; HEMAIS, C. A. 0 processo de internacionalização na ótica da Escola Nórdica: evidências empíricas em empresas brasileiras. Revista de Administração Contemporânea, v. 7, n. 1, p. 109-124, 2003.

JOHANSON, J.; VAHLNE, J. E. The internationalization process of the firm: a model of knowledge development and increasing foreign market commitments. Journal of International Business Studies, v. 8, n. 1, p. 23-32, 1977.

KANTER, R. M.; DRETLER, T. D. Global strategy and its impact on local operations: lessons from Gillette Singapore. Academy of Management Executive, v. 12, n. 4, p. 60-68, 1998.

KEEGAN, W. J.; GREEN, M. C. Princípios de marketing global. 2. ed. São Paulo: Saraiva, 2003.

KOGUT, B. International management and strategy. In: PETTIGREW, A.; THOMAS, H.; WHITTINGTON, R. Handbook of strategy and management. 2nd ed. London: Sage, 2002.

KOTLER, P.; ARMSTRONG, G. Princípios de marketing. 2. ed. Rio de Janeiro: Prentice-Hall do Brasil, 1998.

KUAZAQUI, E. Marketing internacional: como conquistar negócios em mercados internacionais. 2. ed. São Paulo: Makron Books, 1999.

LEVITT, T. The globalization of markets. Harvard Business Review, v. 61, p. 92-102, 1983.

MEYER, B. Morales e o Brasil. Diário Catarinense, Florianópolis, 2006.

MINTZBERG, H.; WATERS, J. A. Of strategies deliberate and emergent. Strategic Management Journal, v. 6, n. 3, p. 257-272, 1985.

OHMAE, K. The borderless world: power and strategy in the interlinked economy. 2nd ed. New York: HarperCollins, 1999.

PARKER, B. Evolução e revolução: da internacionalização à globalização. In: CLEGG, S. R.; HARDY, C.; NORD, W. R. Handbook de estudos organizacionais. 2. ed. São Paulo: Atlas, 1999. 
YIN, R. K. Estudo de caso: planejamento e métodos. 2. ed. Porto Alegre: Bookman, 2001. nagement: an introduction to process and method. 2 nd ed. London: Sage, 2002.

ROWLEY, C.; BENSON, J. Convergence and divergence in Asian human resource management. California Management Review, v. 44, n. 2, p. 90-109, 2002.

VAZQUEZ, J. L. Comércio exterior brasileiro. 2. ed. São Paulo: Atlas, 1999.
Recebido: $10 / 11 / 2010$

Received: $11 / 10 / 2010$

Aprovado: $24 / 11 / 2010$

Approved: $11 / 24 / 2010$ 